\title{
The Effects of Methoxychlor on Riffle Invertebrate Populations and Communities
}

\author{
Paul J. Eisele ${ }^{1}$ and Rolf Hartung \\ Department of Environmental Health, University of Michigan \\ Ann Arbor, Michigan 48104
}

\begin{abstract}
A study was conducted to evaluate the chronic effects of a toxicant on interacting stream invertebrate populations. The study involved the continuous dosing of a small stream at $0.2 \mu \mathrm{g} /$ liter methoxychlor for over one year. Invertebrate populations were monitored by artificial substrate and bottom sample collections of riffle invertebrates.

Most invertebrate populations experienced some reduction due to the stream dosing. Some taxa (baetids and plecopterans) were affected as reflected by population reductions in dosed areas. Many taxa (hydropsychids, simulids, and aeschnids) were temporarily affected, experienc. ing initial population reductions in dosed areas but then recovering to control levels. Other taxa (chironomids and elmids) were not affected by the pesticide dosing.

The riffle invertebrate community colonizing artificial substrates experienced a temporary decrease in diversity through both reduced richness and evenness. Diversity was not decreased in bottom sample collections. In general, most long-term effects were minor in comparison to naturally occurring phenomena such as flooding.
\end{abstract}

Many authors have studied the effects of forest and agricultural pesticide applications on stream invertebrates (Hynes and Williams 1962; Moye and Luckman 1964; Hitchcock 1965; Dimond 1967). Many of these studies indicated high catastrophic invertebrate drift and significant population reductions of plecopterans, trichopterans, and, in some cases, dipterans, that could be attributed to pesticides.

Controlled dosage spraying programs directed at aquatic pests have been more illuminating. These have been aimed at eliminating fish (Cook and Moore 1969) or at controlling or eliminating the larvae of Simuliidae (Burdick et al. 1968; Kershaw et al. 1968), thus affecting non-target riffle invertebrates. The simulid studies indicated that simulids could be temporarily eliminated without a significant permanent reduction in other invertebrates. To date, no studies have monitored the potential effects of controlled, low level pesticide exposure on stream invertebrate communities. Therefore, the present study was designed to investigate the chronic effects of a chlorinated hydrocarbon insecticide (methoxychlor) on stream invertebrate populations and communities.

\footnotetext{
${ }^{1}$ Present address: Engineering Research Department, The Detroit Edison Company, 2000 Second Avenue, Detroit, Michigan 48226.
}

\section{STUDY AREA}

The study was conducted in a tributary of the Saline River in the Raisin River Basin of southeastern Michigan. Abandoned pastures and woodlands border the stream. Stream flow averaged $0.14 \mathrm{~m}^{3} / \mathrm{s}$ (range: $0.014 \mathrm{~m}^{3} / \mathrm{s}$ to $1.132 \mathrm{~m}^{3} / \mathrm{s}$ ). Although the stream is springfed, dissolved oxygen levels and temperature were indicative of a marginally heterotrophic warm water stream. Dissolved oxygen levels ranged from a daytime high of $13.5 \mathrm{mg} / \mathrm{liter}$ to a nighttime low of $3.2 \mathrm{mg} /$ liter. Highest temperatures recorded in riffles and pools were $26 \mathrm{C}$ and $28 \mathrm{C}$, respectively.

Alkalinity, $\mathrm{pH}$, and nutrient levels were monitored during the sampling period. There was no indication of any water quality differences between dosed and control areas since dissolved phosphate $\left(\mathrm{PO}_{4}\right)$, total phosphorus as phosphate, ammonia $\left(\mathrm{NH}_{3}\right)$, nitrite $\left(\mathrm{NO}_{2}\right)$, and chloride $(\mathrm{Cl})$ levels were similar upstream and downstream for the duration of the experiment (Table 1).

Five riffle areas were chosen for sampling along a 400-m length of the stream. Two areas were located above and three below the point of pesticide entry (Table 2).

\section{METHODS}

The stream was chronically dosed with pesticide, using a mechanical dosing apparatus 
TABLE 1.-Chemical parameters ${ }^{\text {a }}$ monitored monthly in the experimental section of the stream over one year of dosing.

\begin{tabular}{|c|c|c|c|c|c|c|c|c|c|}
\hline \multirow[b]{3}{*}{ Parameter } & \multirow{3}{*}{$\begin{array}{c}\text { Number of } \\
\text { samples }\end{array}$} & \multicolumn{8}{|c|}{ Stream sections } \\
\hline & & \multicolumn{4}{|c|}{ Control } & \multicolumn{4}{|c|}{ Dosed } \\
\hline & & Mean & $\mathrm{SE}$ & Maximum & Minimum & Mean & SE & Maximum & Minimum \\
\hline Methoxychlor ( $\mu \mathrm{g} /$ liter $)$ & 30 & 0.0 & & & & 0.2 & 0.015 & 0.37 & 0.09 \\
\hline pH & 24 & 8.0 & 0.1 & 8.4 & 7.4 & 8.2 & 0.1 & 8.7 & 7.3 \\
\hline Alkalinity ( $\mathrm{mg} /$ liter) & 24 & 211 & 9 & 286 & 125 & 214 & 9 & 292 & 121 \\
\hline Dissolved $\mathrm{PO}_{4}(\mu \mathrm{g} /$ liter $)$ & 13 & 58.4 & 8.4 & 111.9 & 22.0 & 59.9 & 11.3 & 131.2 & 15.0 \\
\hline Total $\mathbf{P}$ as $\mathrm{PO}_{4}(\mu \mathrm{g} /$ liter $)$ & 13 & 94.2 & 18.0 & 217.7 & 23.7 & 98.9 & 20.4 & 254.6 & 18.9 \\
\hline $\mathrm{NH}_{3}(\mu \mathrm{g} /$ liter $)$ & 13 & 70.2 & 10.1 & 131.1 & 23.9 & 77.2 & 11.3 & 124.0 & 25.7 \\
\hline $\mathrm{NO}_{2}(\mu \mathrm{g} /$ liter $)$ & 13 & 30.7 & 7.4 & 77.7 & 9.4 & 28.1 & 6.8 & 75.0 & 4.9 \\
\hline $\mathrm{NO}_{3}^{2}(\mathrm{mg} /$ liter $)$ & 13 & 2.03 & 0.22 & 3.36 & 0.83 & 2.00 & 0.24 & 3.20 & 0.84 \\
\hline $\mathrm{Cl}$ (mg/liter) & 13 & 23.7 & 2.0 & 41.3 & 15.1 & 22.7 & 2.2 & 41.9 & I1.9 \\
\hline
\end{tabular}

"All analyses were performed using standard procedures (American Public Health Association 1971).

(Eisele 1975). Methoxychlor (100 percent, 91.2 percent $p, p^{\prime}$ isomer) was added in an acetone water solution $(2: 5)$ with sufficient emulsifying agent (Triton X-100) to ensure dissolution of the methoxychlor in the stream water. The dosing level was fixed at $0.2 \mu \mathrm{g} /$ liter because chronic laboratory bioassays on Cheumatopsyche sp., Gammarus pseudolim. neaus, and Stenonema spp. (Merna and Eisele 1973 ) indicated a monthly median tolerance limit (TLm) of approximately $0.2 \mu \mathrm{g} /$ liter.

Methoxychlor concentrations in the water were monitored periodically at one control and two dosed stations. Water samples were extracted with $50 \mathrm{ml}$ of redistilled hexane in 1-liter graduated cylinders by means of a Teflon impeller system (Kawahara et al. 1965). A 10-ml sample of the hexane was evaporated and subsequently analyzed on a Varian Aerograph Model 1200 gas chromatograph with an electron capture detector.

The dosing system was operated from July 18, 1972 to July 29, 1973. Due to the nature of the dosing system and erratic rainfall pattern, the dosing was not absolutely continuous. Several periods of flooding due to intense

TABLE 2,-Description of stress sampling stations and their locations relative to the dosing location $(+=$ upstream; - = downstream).

\begin{tabular}{clc}
\hline $\begin{array}{c}\text { Station } \\
\text { no. }\end{array}$ & Description & $\begin{array}{c}\text { Distance from } \\
\text { dosing location } \\
(\mathrm{m})\end{array}$ \\
\hline 1 & Control riffle & +245 \\
2 & Control riffle & +63 \\
3 & Dosed riffle & -40 \\
4 & Dosed rifle & -150 \\
5 & Dosed riffle & -150 \\
\hline
\end{tabular}

rainfall and heavy thaws caused stoppages in dosing as did unusually rapid temperature fluctuations.

The mean methoxychlor concentration for dosed stations was $0.2 \mu \mathrm{g} /$ liter (Table 1). At Station 3, $40 \mathrm{~m}$ downstream from the doser, the mean pesticide concentration was $0.17 \pm$ $0.04 \mu \mathrm{g} /$ liter, while $102 \mathrm{~m}$ downstream, it was $0.23 \pm 0.02 \mu \mathrm{g} /$ /iter. Lowest pesticide levels were usually measured during periods of high stream turbidity. Apparently, the methoxychlor was adsorbed by suspended solids and removed from the water column. The measured methoxychlor concentrations occasionally differed at the two dosed stations, primarily because of the close proximity of Station 3 to the doser. At low stream flow, mixing was complete at this station, but at higher stream flow this was not the case.

Riffle invertebrates were allowed to colonize on artificial substrates for 30-day periods. Four $460 \cdot \mathrm{cm}^{2}$ multiple plate samplers (Hester and Dendy 1962) were placed in each of the five transects which crossed two control and three dosed riffles. The plate samplers were anchored within $10 \mathrm{~cm}$ of the stream bottom. The plates were constructed of $0.65-\mathrm{cm}$ masonite and were used to provide a homogeneous habitat on which to detect control and dosed population differences. This reduced stationrelated differences due to substrate. Samples were collected by surrounding the sampler with a plastic bag and withdrawing the enclosed sampler from the water. Plate samplers were collected twice monthly in summer and monthly during the rest of the year. Nineteen sets of plate samplers were collected, one set 


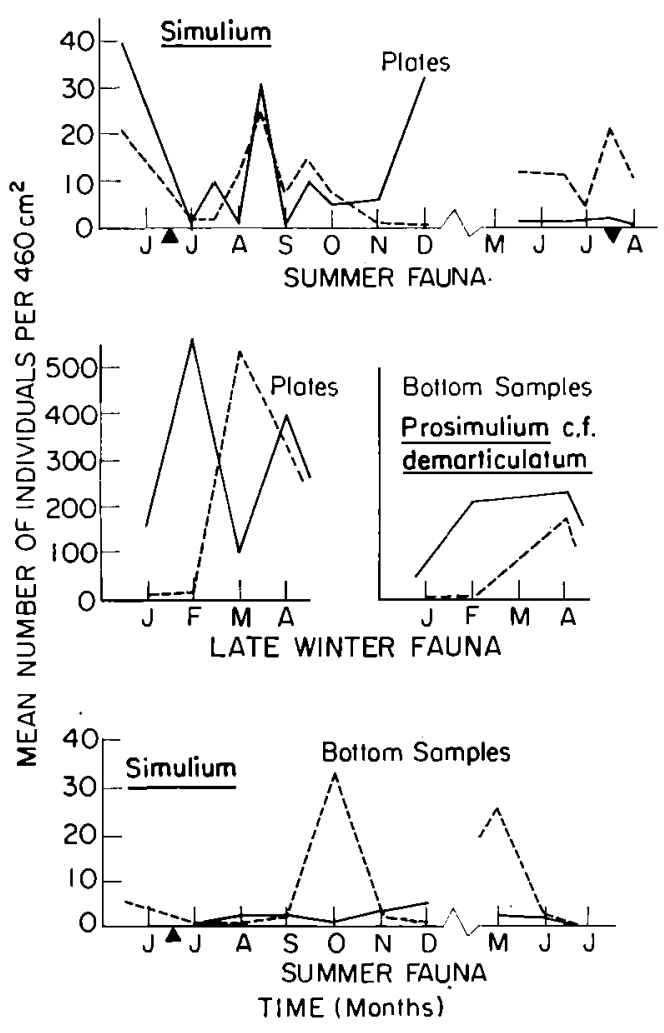

FIGURE 1.-Mean control and mean dosed population fluctuations of Simuliidae per $460 \mathrm{~cm}^{2}$ over the year of dosing ( $\mathbf{\Delta}$ ) dosing initiated, ( $\mathbf{\nabla}$ ) dosing stopped, (-) mean control population size, (--.) mean dosed population size.

prior to dosing, seventeen during dosing, and one shortly after dosing was terminated. In some cases, flooding affected sampling by preventing collection or scouring out individual samplers.

Monthly bottom samples were collected in control and dosed areas using a $460 \cdot \mathrm{cm}^{2}$ sampler constructed of Number 471 Nitex similar to that described by Waters and Knapp (1961) to supplement plate sampler collections. Both plate and bottom samples were preserved in 10 percent formalin. The preserved invertebrates from plate and bottom samples were identified to species or lowest identifiable taxon and enumerated.

Population fluctuations over the year of dosing were determined for selected taxa by using the mean number of individuals at Stations 1 and 2 to represent the control areas, and the mean at Stations 4 and 5 to represent the dosed areas. Comparisons were made of control and dosed population means by plotting these means over the sampling time.

Differences in community structure between control and dosed stations were monitored by measurements of species diversity using the equations of Shannon and Weaver (Pielou 1969). Mean diversity for the two control and two dosed stations $\left(H^{\prime}\right)$ as well as species richness $(S)$ and evenness $\left(J^{\prime}\right)$ were calculated for bottom samples and plate samples.

\section{RESULTS AND DISCUSSION}

Over 77 taxa were collected from bottom and plate samplers. Of these only four taxa were not found in dosed riffles. The number of taxa collected from each sample ranged from 5 to 30 . Usually, about 25 taxa were represented per station. Fluctuations in dosed and control populations were variable over time for all major taxa. Control and dosed simulid populations varied temporally in both plate samplers and bottom samples (Fig. 1). The dosed populations of both the summer fauna, Simulium vittatum, and winter fauna, Prosimulium c.f. demarticulatum, were apparently not substantially decreased. The fluctua. tion of Prosimulium population density between dosed and control areas in February and March was probably more a result of a time lag in colonization of dosed plate samplers from upstream control areas rather than an observable pesticide effect. These results are consistent with those of Wallace and Brady (1971) who found S. vittatum present below a continuous $10 \mu \mathrm{g} /$ liter industrial dieldrin effluent. These results indicate that continuous application of methoxychlor at low concentrations is not effective in controlling simulids.

Population fluctuations of other selected taxa are shown in Figure 2. Because of the similarity in trends of bottom samples and plate samplers only the results of plate samplers are shown. Both control and dosed populations of most taxa were reduced from fall through winter due to flooding resulting from increased runoff from heavy rains and early winter thaws.

Most taxa exposed to dosing exhibited a slight decrease in population density at the 

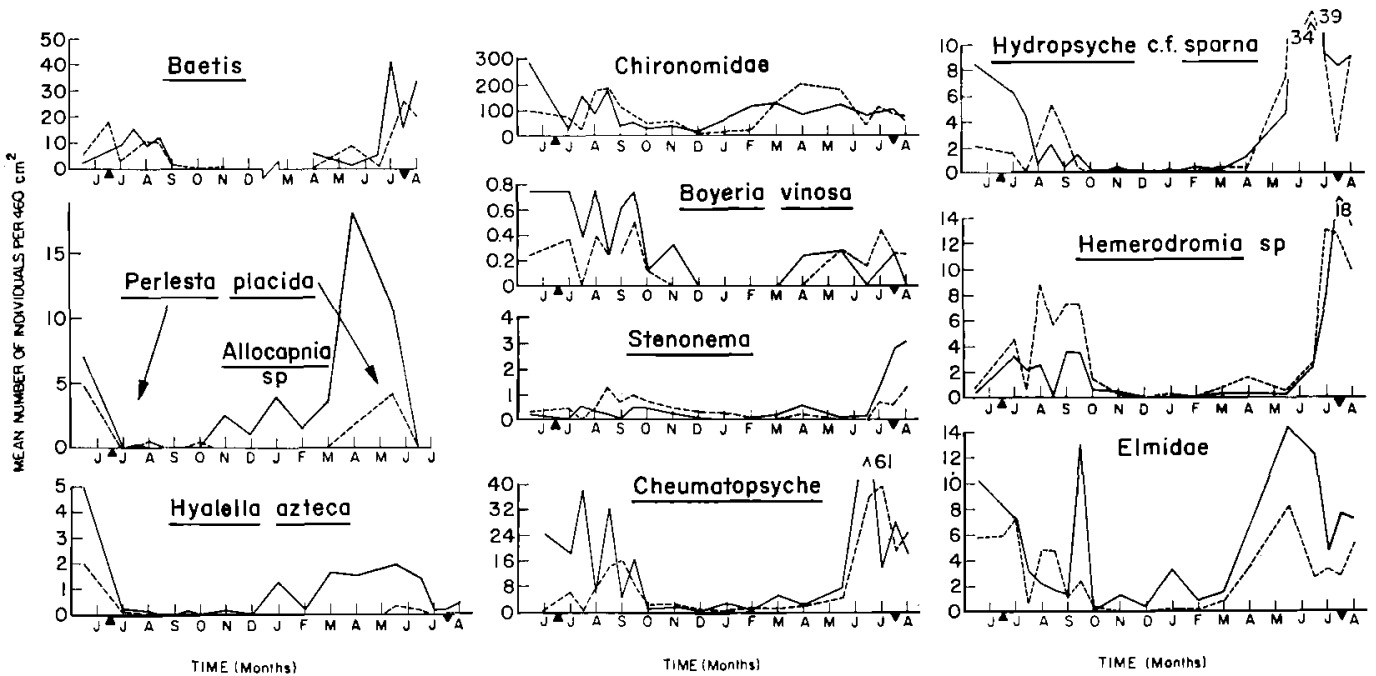

FIGURE 2.-Mean control and mean dosed population fluctuations of selected aquatic invertebrate taxa per 460 $\mathrm{cm}^{2}$ over the year of dosing ( $\left.\mathbf{\Delta}\right)$ dosing initiated, $(\boldsymbol{\nabla})$ dosing stopped, (-) mean control population size, (---) mean dosed population size.

time dosing was initiated or shortly thereafter. Baetis species (primarily $B$. intercalaris and some $B$. levitans), the plecopterans (Perlesta placida, Allocapnia sp., and some Isoperla sp.), and Hyalella azteca appeared to be most affected by the methoxychlor dosing which is consistent with the results of other studies involving chlorinated hydrocarbon pesticides (Moye and Luckman 1964; Hynes and Williams 1962). These taxa were not permanently eliminated in dosed areas but the dosed populations of plecopterans and amphipods were substantially reduced. Hyalella azteca was not observed in dosed riffles for nine months of the twelve-month pesticide dosing period. Dosed populations of hydropsychids, $\mathrm{Hydro}$ psyche c.f. sparna and Cheumatopsyche spp., experienced initial reductions when exposed to methoxychlor but quickly recovered even though the exposure was continuous. Hitchcock (1965) observed that hydropsychids, especially Cheumatopsyche, were susceptible to DDT and slow to recover in both field and laboratory studies. Merna and Eisele (1973) observed a 28-day TLm of $0.2 \mu \mathrm{g}$ /liter for methoxychlor in laboratory bioassays with the same species of Cheumatopsyche that occurred in the dosed stream. Other field studies involving aldrin (Moye and Luckman 1964) and dieldrin (Wallace and Brady 1971) indicated that hydropsychids were not susceptible to chlorinated hydrocarbon pesticides. The discrepancy between these field studies is probably due to species differences in sensitivity to different pesticides.

A similar difference in field sensitivity and laboratory sensitivity to methoxychlor was also observed for Stenonema (Fig. 2). The 28-day TLm was $0.2 \mu \mathrm{g} /$ /iter, while this concentration in field dosage resulted in a slightly increased dosed population. This difference may be due to vigor tolerance, reported for Stenonema (Grant and Brown 1967), or due to a behavioral response resulting in avoidance of pesticide exposure in the natural environment.

The aeschnid (Boyeria vinosa), dipterans, both chironomids and empidids (Hemerodromia sp.), and elmid beetle adults and larvae, were not sensitive to methoxychlor. This tolerance was also observed in previous field studies with other pesticides (Hitchcock 1965; Moye and Luckman 1964). In this study the dosed population of Hemerodromia increased during stream dosage. This may have been a result of reduced competition from other predators, stress induced vigor, or increased prey (chironomids) density. 


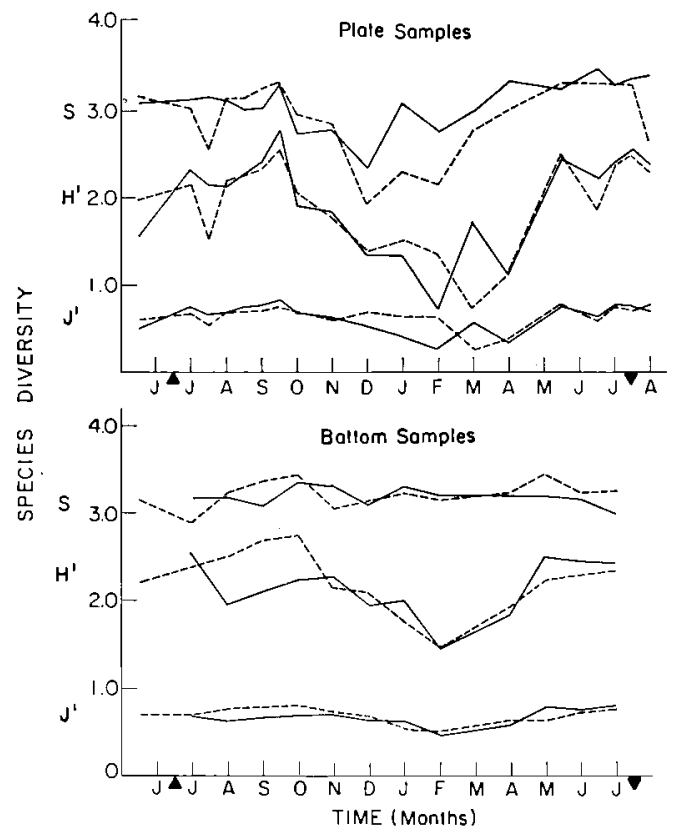

FIGURE 3.-Species diversity $\left(\mathrm{H}^{\prime}\right)$, evenness $\left(\mathrm{J}^{\prime}\right)$, and species richness (S) of invertebrate communities collected in plate samples and bottom samples from dosed and control stations ( $\mathbf{\Delta}$ ) dosing initiated, ( $)$ dosing stopped, (-) mean control population size, (----) mean dosed population size.

Changes in species diversity $\left(H^{\prime}\right)$ on plate samplers (Fig. 3) were comparable to individual population changes observed in Figure 1. When dosing was initiated, diversity decreased because of reduced species richness $(S)$ and reduced population densities ( $J^{\prime}$, evenness). Otherwise, changes in diversity in control and dosed areas were due to nondoserelated environmental factors, including flooding and natural variation (Hynes et al. 1974). The large variation in both diversity and evenness in February and March was due to the lag in colonization of Prosimulium in dosed areas. These nondose-related environmental conditions resulted in a greater change in diversity over time at both control and dosed stations than did the pesticide dosing.

Species diversity was less variable in bottom collections than plate samplers over time (Fig. 3. Initially, the dosed stations had greater diversity because richness and evenness were lower upstream. This effect was not dose related, as predosing samples indicated an increasing trend in dosed area diversity. After the fall of 1972, however, there was little difference in dosed and control stations. The bottom invertebrates were not as affected by flooding as those on plate samplers. This could be expected because the invertebrates on the plate samplers were in the water column and, thus, exposed to the faster currents.

Most invertebrates were negatively affected to some extent at the initiation of stream dosing as measured by plate samplers. This phenomenon could have been due to reduced activity on the stream bottom since invertebrate populations in bottom samples did not show similar decreases at dosing. Reduced activity would lead to reduced colonization on plate samplers. This phenomenon was shortlived, however, and in both cases the density usually returned to predosing levels within a month. This may imply some type of compensatory mechanism in certain taxa to overcome the initial stress of a newly introduced low-level toxicant and its effect over time.

A continuous low-level methoxychlor stress results in response patterns at the population level different from those at the community level. The population response indicates that some species have a low tolerance for methoxychlor and could be used as indicator organisms of low-level pesticide stress. These sensitive species were not completely eliminated, but the population density was reduced. The community response (as measured by species diversity) indicated that the dosing resulted in no substantial change in diversity.

A continuous low-level methoxychlor stress affects stream invertebrate populations subtly and not as much as extreme natural environmental stresses. By far the greatest impact on invertebrate populations and community structure in this study was current velocity extremes resulting from flooding. The more subtle pesticide effects were partially masked by the flooding.

This does not imply that exposure of benthic invertebrate communities to a toxicant was not disruptive. For example, in this study, subtle population shifts resulted in a changed benthic community. This change, however, was probably short-lived as intolerant species were not eliminated. Thus, recolonization by intolerant 
species would be rapid once the source of stress was discontinued.

\section{ACKNOWLEDGMENTS}

The authors wish to thank the staffs of the Institute for Fisheries Research, Michigan Department of Natural Resources, and the Environmental Research Laboratory, U.S. Environmental Protection Agency, for critical review of the manuscript. We also wish to thank the E. I. duPont de Nemours Company of Wilmington, Delaware, for supplying methoxychlor.

This work is based on a Ph.D. thesis submitted by P. J. Eisele to the graduate faculty of the University of Michigan, Ann Arbor, in 1974. Financial support was provided in part by U.S. Environmental Protection Agency grants (u910010 and 18050 DL0).

\section{LITERATURE GITED}

American Public Health Association. 1971. Standard methods for the examination of water and waste water. 13 th ed. New York. $769 \mathrm{pp}$.

Burdick, G. E., H. J. Harris, J. Skea, C. Frisa, and C. SWEeney. 1968. Methoxychlor as a blackfly larvicide, persistence of its residues in fish and its effect on stream anthropods. N.Y. Fish Game J. $15(2)$ : 121-142.

Cook, S. F., and R. L. Moore. 1969. The effects of a rotenone treatment on the insect fauna of a California stream. Trans. Am. Fish. Soc. 98: 539-544.

Drmond, J. B. 1967. Pesticides and stream insects. Maine Forest Serv. Conserv. Foundation Bull. 23. 21 pp.

Eisele, P. J. 1975. A simple dosing system for continuous stream dosing. Trans. Am. Fish. Soc. $104(2)$ : 359-362.
Grant, C. D., and A. W. A. Brown. 1967. Development of DDT resistance in certain mayflies in New Brunswick. Can. Entomol. 99: 1040-1050.

Hester, F. E., and J. S. Dendy. 1962. A multipleplate sampler for aquatic macroinvertebrates. Trans. Am. Fish. Soc. 91: 420-421.

Hiтсігсоск, S. W. 1965. Field and laboratory studies of DDT and aquatic insects. Conn. Agric. Exp. Sta. New Haven Bull. 668: 1-32.

Hynes, H. B. N., and T. R. Williams. 1962. The effect of DDT on the fauna of a central African stream. Ann. Trop. Med. Parasitol. 56: 78-91.

, N. K. Kaushik, M. A. Lock, D. L. Lush, Z. S. J. Stocker, R. R. W Allace, AND D. D. Williams. 1974. Benthos and allochthonous organic matter in streams. J. Fish. Res. Board Can. $31: 545-553$.

Kawahara, F. K., I. W. Eichelberger, B. H. Reid, AND H. StierLI. 1965. Semi-automatic extraction of organic materials from water. Public Health Service Water Pollution. Surveillance System Application and Development Report. $27 \mathrm{pp}$.

Kershaw, W. E., T. R. Williams, S. Frost, R. E. Matchett, M. L. Mills, and D. R. Johnson. 1968. The selective control of Simulium larvae by particulate insecticides and its significance in river management. Trans. R. Soc. Trop. Med. Hyg. 62: 35-40.

Merna, J. W., and P. J. Eisele. 1973. The effects of methoxychlor on aquatic biota. EPA-R3-73046. Ecological research series. U.S. Environ. Prot. Agency. p. 59

Moye, W. C., ANd W. H. Luckman. 1964. Fluctuations in populations of certain aquatic insects following application of Aldrin granules to Sugar Creek, Iroquois County, Illinois. J. Econ. Ent. 57: 318-322.

Pielou, E. C. 1969. An introduction to mathematical ecology. John Wiley and Sons. $286 \mathrm{pp}$.

Wallace, J. B., and W. E. Brady. 1971. Residue levels of dieldrin in aquatic invertebrates and effect of prolonged exposure on population. Pestic. Monit. J. 5: 295-300.

W aters, T. F., and R. J. KNapP. 1961. An improved stream bottom fauna sampler. Trans. Am. Fish. Soc. 90: 225-226. 